\section{Calibration assessment of forest flammability potential in Italy}

\author{
Piermaria Corona ${ }^{(1)}$, Barbara Ferrari ${ }^{(2)}$, Rosaria Cartisano ${ }^{(2)}$, Anna \\ Barbati ${ }^{(2)}$
}

Fuel flammability is defined as the relative ease with which a fuel will ignite and burn with a flame. Different forest types have different intrinsic "baseline" flammabilities, depending on the susceptibility to burn of the main tree species that build up the forest cover. In this perspective, we apply a foresttype based approach to classify and map the flammability level of the forests in Italy. Baseline forest type-based flammability values provided at European level have been assigned to a national forest types map, derived from Corine Land Cover 2006. Flammability values have been then further calibrated against the Burned Area Selection Ratio, a measure of the actual incidence of wildfires among different forest types. Accordingly, a calibrated flammability index was derived by simple linear regression, so that predicted flammability reflects more accurately the observed fire incidence among different forest types in Italy. Findings show that the flammability of forest types ranges from low to high: on average, the $17 \%$ of the forest cover has medium to high flam mability, with wide regional variability. Notably, in four Regions (Sardegna, Sicilia, Puglia, Calabria) over one third of total forest area has medium to high flammability. Large scale mapping of forest flammability is crucial to define long-term priorities among forest areas as to how to distribute fire management effort. Areas falling into medium to high flammability classes should be given priority for implementing fuel management treatments in order to mitigate fire hazard from the stand to the landscape scale.

Keywords: Fuel Flammability, Fire Hazard, European Forest Types, Burned Area Selection Ratio, Fire Management

\section{Introduction}

Fuel flammability is defined as the relative ease with which a fuel will ignite and burn with a flame (Stacey et al. 2012). It plays a paramount role in the reaction of wildland fuels to heat exposure, thus influencing the spatial pattern of fire ignition risk. Accordingly, flammability is a key determinant of fire hazard, i.e., the degree of both ease of ignition and fire suppression difficulty of the fuels (FAO 2006).

According to Anderson (1970) and Trabaud (1976), flammability can be defined through three variables that describe how well the fuel ignites (ignitibility), how well it

(1) Consiglio per la Ricerca e la sperimentazione in Agricoltura, Forestry Research Centre (CRA-SEL), v.le S. Margherita 80, Arezzo (Italy); (2) Department for Innovation in Biological Agro-food and Forest systems (DIBAF), University of Tuscia, via San Camillo de Lellis snc, I01100 Viterbo (Italy)

@ Anna Barbati (barbati.sisfor@unitus.it)

Received: Sep 10, 2013 - Accepted: Mar 06, 2014

Citation: Corona P, Ferrari B, Cartisano R, Barbati A, 2014. Calibration assessment of forest flammability potential in Italy. iForest 7: 300-305 [online 2014-05-07] URL:

http://www.sisef.it/iforest/contents/?id=ifor1123-007

Communicated by: Raffaele Lafortezza ty components can be measured by laboratory and field experiments (e.g., Madrigal et al. 2009), translation of laboratory results to field conditions is highly problematic (Fernandes \& Cruz 2012). Moreover, field experiments are usually expensive (White \& Zipperer 2010)

As a matter of fact, many variables do affect fuel flammability at leaf, plant and forest stand level, including structural characteristics of the fuels, moisture content, chemical composition and fuel spatial arrangement (Xanthopoulos et al. 2012). The interplay of forest composition and stand structure is crucial to influence forest fuel flammability at stand scale. On one hand, the "baseline" flammability level of a forest type is primarily driven by the fuels produced by the main tree species that build up the forest cover. On the other hand, fire hazard might be widely variable even in stands composed of flammable forest species, depending on forest stand structure and fuel accumulation (Fernandes 2009).

Considering that fire management resources are limited, it is crucial to provide fire managers with operational methodologies to assess fire hazard over large forest areas (a country or a region). A landmark approach to fire hazard mapping is fire behavior modeling. Fuel models are mathematical representations of fuel properties within a specified location (Stacey et al. 2012), used to predict and plot likely fire spread and intensity by means of fire behavior models, packaged into decision support systems (e.g., FARSITE - Finney 1998, BehavePlus Heinsch \& Andrews 2010). However, the implementation of fire modeling on a large scale is inherently limited by the difficulty and high cost of yielding accurate geospatial data on fuels (Keane et al. 2001). In this perspective, a large scale map of forest flammability potential can be a valuable decision support tool to assess need and priorities in fire management, e.g., to support the effectiveness of fire prevention, detection and allocation of fire fighting resources (Blasi et al. 2005). Following this line, the paper presents a methodological framework to classify and map the flammability level of main Italian forest types by processing spatial data on forest cover composition and recent fire history. Baseline forest type-based flammability values provided at European level by Xanthopoulos et al. (2012) have been calibrated against the Burned Area Selection Ratio (BASR), a measure of the actual incidence of wildfires among different forest types (Bovio et al. 2014).

\section{Study area}

Land covered by forests in Italy (sensu FAO 2001) amounts to 8.8 millions of hectares, nearly $30 \%$ of the country's terri- 
Tab. 1 - Baseline flammability of main forest types in Italy according to the assessment scheme by Xanthopoulos et al. (2012).

\begin{tabular}{llc}
\hline $\begin{array}{l}\text { Corine Land Cover } \\
\text { (2006) forest types }\end{array}$ & European Forest Type Classification & $\begin{array}{c}\text { Flammability } \\
\text { index }\end{array}$ \\
\hline $\begin{array}{l}\text { Broad-leaved } \\
\text { evergreen forest }\end{array}$ & 9.1 Mediterranean evergreen oak forest & 3.4 \\
\hline $\begin{array}{l}\text { Deciduous oak } \\
\text { forest }\end{array}$ & $\begin{array}{l}\text { 8.1 Downy oak forest } \\
\text { 8.2 Turkey oak forest }\end{array}$ & 2.05 \\
\hline $\begin{array}{l}\text { Other broad-leaved } \\
\text { forest }\end{array}$ & 8.8 Other thermophilous deciduous forests & 2.5 \\
\hline Chestnut forest & 8.7 Chestnut forest & 2.7 \\
\hline Beech forest & 7.3 Apennine-Corsican mountainous beech forest & 2 \\
\hline $\begin{array}{l}\text { Mediterranean pine } \\
\text { forest }\end{array}$ & 10.1 Mediterranean pine forest & 4.1 \\
\hline $\begin{array}{l}\text { High oro-Mediter- } \\
\text { ranean pine forest }\end{array}$ & $\begin{array}{l}\text { 10.2 Mediterranean and Anatolian black pine forest } \\
\text { 10.4 Mediterranean and Anatolian black pine forest }\end{array}$ & 2.95 \\
\hline 10.5 Alti-Mediterranean Pine forest & \\
\hline $\begin{array}{l}\text { Spruce/fir forest } \\
\text { pine forest }\end{array}$ & 10.6 Mediterranean and Anatolian fir forest & 2 \\
\hline
\end{tabular}

tory (INFC 2007). The most widespread forest types are dominated by oaks, beech and chestnut, each exceeding one million hectares; spruce-dominated woodlands are the most extensive coniferous forests $(0.6$ millions of hectares).

The total amount of aboveground biomass and deadwood shows significant differences between broadleaved and coniferous dominated forest types (INFC 2009): on average, it is lower $\left(60-130 \mathrm{Mg} \mathrm{ha}^{-1}\right)$ in oak forests, chestnut and Turkey oak forests, due to coppice forest management, than in forest formations dominated by coniferous species (80-240 Mg ha $\left.{ }^{-1}\right)$. Deadwood accumulation mainly depends on the level of silvicultural abandonment and/or on the age of forest stands, ranging from $3 \%$ (beech forest, altimediterranean pine forest, Turkey oak forest, Italian oak forest, Macedonian and Valonian oak forest, cork oak forest) to $12 \%$ (chestnut and Turkey oak forests) of the total above-

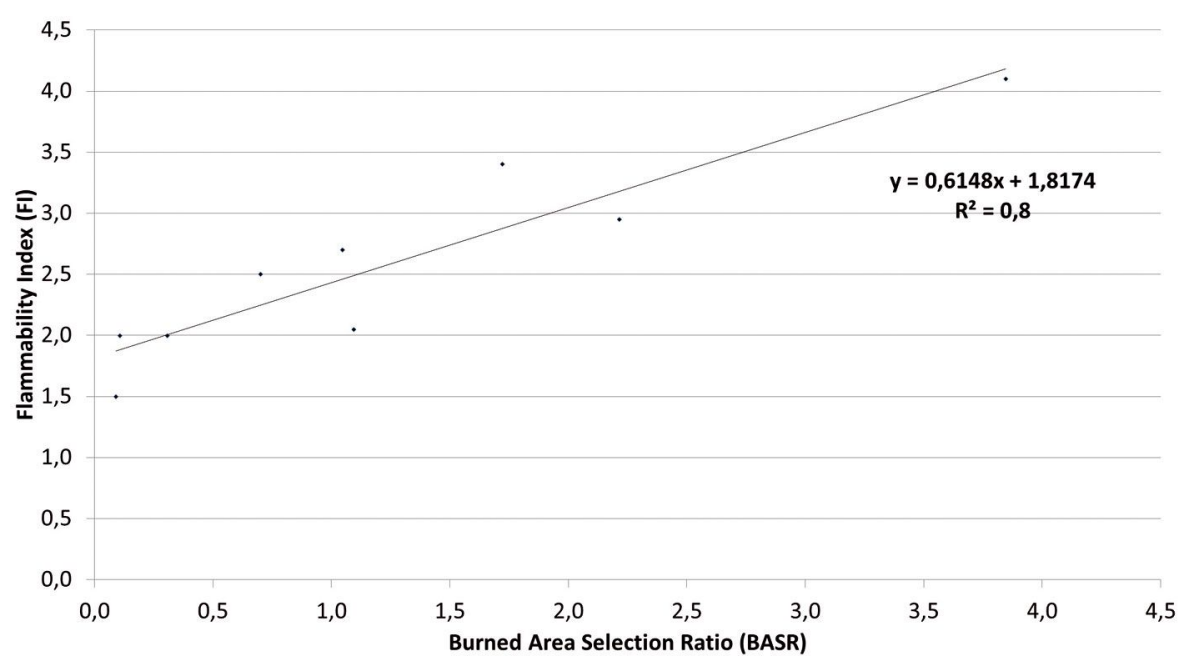

Fig. 1 - Correlation between the flammability index $(F I)$ and the burned area selection ratio $(B A S R)$ for the forest types reported in Tab. 1. computer assisted visual interpretation of satellite images (Landsat series). CLC standard nomenclature maps forest cover in three classes (broadleaves, coniferous and mixed forest). However, as part of the national implementation activities of the CLC project, a fourth hierarchical level has been introduced in Italy since CLC 2000 to map forest and semi-natural areas with a higher thematic detail (ISPRA 2010). Accordingly, the three third-level forest classes can be further classified into nine main forest types based on the dominant forest species (see Tab. 1).

In order to quantify the actual incidence of wildfires amongst forest types (see BASR index below) we used the vector geodataset of areas affected by wildfires (forest and rural areas) recorded through GPS survey by the Italian National Forest Service (Corpo Forestale dello Stato, CFS). A full time series is currently available for the years 2006-2011 for 15 out of 20 NUTS2 level administrative units of Italy (the geodataset does not cover the five autonomous regions with special statute). The minimum mapping unit of burned areas is $2000 \mathrm{~m}^{2}$, with a number of fire events per year ranging from 1370 (year 2010) to nearly 5000 (year 2007).

\section{Methodology}

The assessment framework proposed by Xanthopoulos et al. (2012) allows to assign a baseline flammability index $(F I)$, reflecting typical fire hazard for 60 vegetation types of Europe and north Africa and their corresponding classes in the European Forest Types (EFTs) classification (Barbati et al. 2014). The whole range of variation of the $F I$ is ranked into five classes (Xanthopoulos et al. 2012):

1. very low $(1<F I<1.8)$ - low flammability even under extreme conditions (e.g., temperature $>38{ }^{\circ} \mathrm{C}$, relative humidity $<15 \%$, windspeed $>30 \mathrm{~km} \mathrm{~h}^{-1}$ );

2. low $(1.8<F I<2.6)$ - flammable under extreme conditions when the number of fire starts can be considerable and the fires quite active;

3. medium $(2.6<F I<3.4)$ - fires can be numerous under hot summer conditions and they are likely to present significant control problems requiring efforts and resources;

4. high $(3.4<F I<4.2)$ - fires are very likely under hot summer conditions; they can escape initial attack if not attacked effectively and then will defy direct frontal attack;

5. very high $(4.2<F I<5.0)$ - fires can be plentiful even under relatively mild fire season conditions; they are likely to escape all but the best initial attack efforts under high fire danger conditions, in which case they will defy direct control efforts at their front until conditions change; under extreme fire weather conditions they can result in mega-fires. 
In order to assign the FI to main Italian forest types, a correspondence between the national forest types map derived from the CLC 2006 and the European Forest Types classification has been established (Tab. 1).

EU level flammability values have been further calibrated against the Burned Area Selection Ratio (BASR). BASR is a measure of actual fire incidence by forest type classes, defined as the ratio between percentage of burned area of a given forest type compared to the total burned forest area and the percentage of the area of the forest type compared to the total forest area (Bovio et al. 2014 - eqn. 1):

$$
B A S R=\frac{A_{B} / T_{B}}{A_{r} / T_{r}}
$$

where $A_{\mathrm{B}}$ is the burned area of the considered forest type, $T_{\mathrm{B}}$ is the total burned forest area, $A_{\mathrm{r}}$ is the area of the considered forest type, and $T_{\mathrm{r}}$ is the total forest area.

A $B A S R$ value higher than 1 indicates that the considered forest type burns more often than would be the case if fires occur randomly. Therefore, the BASR index can be regarded as a robust measure to validate and calibrate baseline flammability values at national scale.

The $B A S R$ was calculated by a GIS operation of geometric intersection of the inputs geodatasets CLC 2006 and 2006-2011 fire perimeters. As repeated burning of forest types dominated by oaks, chestnut or Mediterranean pines has been occurring in Italy in the period 2006-2011 (Barbati et al. 2013), the $A_{\mathrm{B}}$ term was calculated as the sum of the areas of single fire events, occurred in the period 2006-2011, within $A_{\mathrm{r}}$ as mapped by CLC 2006 in the 15 NUTS2 level administrative units.

Regression analysis was then performed to quantify the relationship between $F I$ and $B A S R$ values for the nine forest types classes of the CLC 2006 dataset (Fig. 1). The high value of the coefficient of determination $\left(\mathrm{R}^{2}=0.80\right)$ indicates a good fitting of baseline flammability values $(F I)$ to the observed fire incidence $(B A S R)$. Moreover, the regression line values fall within the range of variability of the flammability index (1-5). Accordingly, a calibrated flammability index (Tab. 2) was derived as a linear function of $B A S R$ (see Fig. 1 equation).

\section{Results and discussion}

All the nine forest types considered in this study were affected by forest fires in the 2006-2011 period, but the total size of area affected by fire and $B A S R$ varies considerably between forest types (Fig. 2). In absolute terms, deciduous oaks and chestnut forests have the highest values of total burned area (over 30000 and 10000 hectares, respectively, in the considered time period). However, the rate of incidence of fire in these
Tab. 2 - Calibrated flammability index for the forest types reported in Tab. 1.

\begin{tabular}{lc}
\hline Corine Land Cover (2006) forest types & Calibrated flammability index \\
\hline Larch and arolla pine forest & 1.87 \\
Spruce/fir forest & 1.88 \\
Beech forest & 2.01 \\
Other broad-leaved forest & 2.25 \\
Chestnut forest & 2.46 \\
Deciduous oak forest & 2.49 \\
Broad-leaved evergreen forest & 2.88 \\
High oro-Mediterranean pine forest & 3.18 \\
Mediterranean pine forest & 4.18 \\
\hline
\end{tabular}

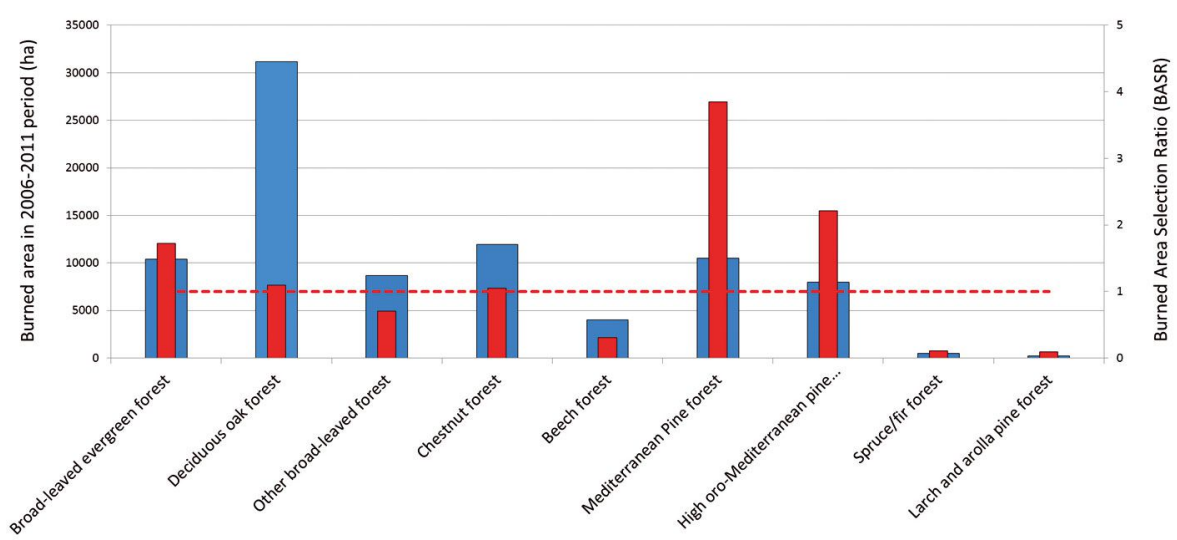

Fig. 2 - Burned area (blue histograms) and $B A S R$ values (red histograms) for the forest types reported in Tab. 1; the red dashed line represents $B A S R=1$ (processed from Italian National Forest Service geodataset on fire perimeters - CFS 2006-2011).

forest types is in balance with their relative

3.85. Mediterranean Pine forests have a discoverage, with a $B A S R$ value close to 1 (see Fig. 2). proportionately high fire occurrence $(B A S R$ $=3.85)$, followed by High oro-MediterraOn the whole, $B A S R$ ranges from 0.09 to nean pine forests $(B A S R=2.21)$ and broad-

Tab. 3 - Relative share of forest area by flammability levels and administrative Regions in Italy.

\begin{tabular}{lcccc}
\hline \multirow{2}{*}{$\begin{array}{l}\text { Rdministrative } \\
\text { Region }\end{array}$} & \multicolumn{3}{c}{ Share of forest area by flammability level (\%) } \\
\cline { 2 - 5 } & low & medium & high & $\begin{array}{c}\text { medium to } \\
\text { high }\end{array}$ \\
\hline Sardegna & 7 & 75 & 18 & 93 \\
Sicilia & 51 & 30 & 19 & 49 \\
Puglia & 57 & 20 & 24 & 43 \\
Calabria & 63 & 33 & 4 & 37 \\
Valle d'Aosta & 75 & 25 & 0 & 25 \\
Toscana & 81 & 16 & 3 & 19 \\
Campania & 83 & 16 & 1 & 17 \\
Basilicata & 85 & 12 & 3 & 15 \\
Umbria & 86 & 12 & 2 & 14 \\
Lazio & 87 & 12 & 1 & 13 \\
Liguria & 91 & 6 & 4 & 9 \\
Trentino Alto Adige & 91 & 8 & 0 & 9 \\
Abruzzo & 94 & 6 & 0 & 6 \\
Friuli Venezia Giulia & 95 & 5 & 0 & 5 \\
Marche & 95 & 4 & 1 & 5 \\
Molise & 97 & 2 & 1 & 3 \\
Veneto & 97 & 3 & 0 & 3 \\
Lombardia & 98 & 2 & 0 & 2 \\
Emilia Romagna & 98 & 2 & 0 & 2 \\
Piemonte & 99 & 1 & 0 & 1 \\
Italy & 83 & 14 & 3 & 17 \\
\hline
\end{tabular}


Fig. 3 - Map of the forest flammability potential in Italy.

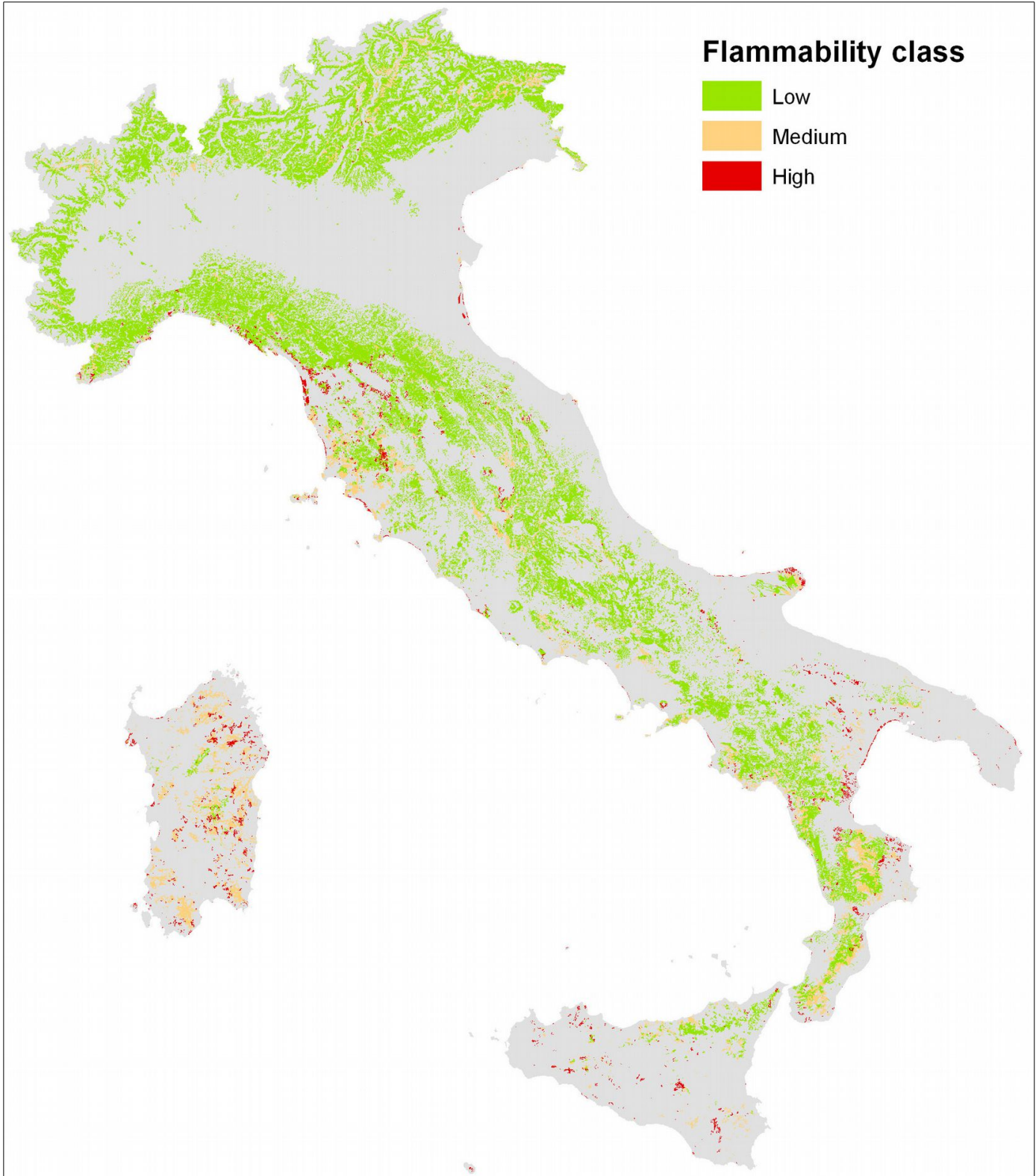

leaved evergreen forests $(B A S R=1.72)$. Although $B A S R$ values of forest types show regional variations, the absolute difference of $B A S R$ national value and average of $B A S R$ regional values is small relative to the range of the index: it ranges from 0.1 (beech forest) to 0.9 (broadleaved evergreen forest). Therefore, BASR national values can be regarded as good predictors of wildfire susceptibility even at regional level.

Tab. 2 reports the calibrated values of the flammability index for each forest type. The calibrated flammability index, building on information on observed fire incidence, represents a more reliable forest type-based rating of forest flammability potential in Italy. The calibration approach adopted here is founded on the principle of resource selection function (sensu Manly et al. 1993 - for relevant applications to forest fires, see Ba- jocco \& Ricotta 2008 and Pezzatti et al. 2009), thus providing the baseline flammability values with a likelihood based on recent fire history. This puts forward a significant improvement in the quantification of flammability proposed by Xanthopoulos et al. (2012), which is based on expert assessment and consequently has a component of subjectivity. On the other hand, it is worth noting that the absolute value of the differences between the calibrated values and the baseline proposed by Xanthopoulos et al. (2012) are not higher than 0.5 , and that such small a deviation does not change the ranking of forest types flammability values into the five classes, except for chestnut forest (baseline: medium; calibrated: low flammability).

The approach proposed here has not been conceived to replace fire behavior modeling, which objectively quantify the potential for burning, but it is not still operational for fire hazard mapping over large forest areas, although the cost of mapping fuel models could be considerably reduced in the future by more widespread availability of Airborne Laser Scanning data (e.g., García et al. 2010, Chirici et al. 2013).

The operational outcome of the proposed methodology is rather the stratification of fire hazard in terms of forest flammability potential assessed from forest type maps, which are usually available over large areas, as shown in Fig. 3. Based on this approach, fire hazard can be quantified for any given territorial units, e.g., NUTS2 administrative Regions (Tab. 3). The flammability of the forests proves to be extremely variable across the country: on average, $17 \%$ of the forest cover has medium to high flammabi- 
lity, with wide regional variability. Notably, in four regions (Sardegna, Sicilia, Puglia, Calabria) over one third of total forest area has medium to high flammability.

\section{Conclusions}

Fire ignition risk and fire hazard over large forest areas are primarily determined by flammability of forest fuels. It is impossible to modify these characteristics at a reasonable cost, but it is possible to provide fire managers with information on priority areas, i.e., those with high fire hazard. In these areas, optimizing fuel treatment techniques, like prescribed burning, may be very effective to achieve fire hazard reduction goals (Ascoli \& Bovio 2013). These practices are even more strategic in landscape settings and forest types affected by short-term fire wildfire recurrence (Barbati et al. 2013).

In this perspective, the methodological approach proposed by this study offers a significant contribution. Calibration of forest type-based baseline values of forest flammability against the Burned Area Selection Ratio can be regarded a robust procedure to evaluate and compare the fire hazard potential between different forest types and to map their flammability levels over large forest areas accordingly. Furthermore, the proposed methodological approach can be easily applied also in other Mediterranean countries, like e.g., Spain, Portugal and Greece, where forest types maps and geospatial information on forest fire perimeters are available (Chiriacò et al. 2013).

Large scale mapping of forest flammability can result in significant improvements in fire management: it provides information about the (static) spatial pattern of fire hazard over a country or a region. Such information is essential to define long-term priorities among forest areas as to fire management effort. For instance, areas falling into medium to high flammability classes at regional level should be given priority for fire prevention, i.e., for planning and implementing fuel management treatments to mitigate fire hazard from the stand to landscape scale (Leone et al. 2000). At the same time, knowledge of spatial pattern of fire hazard can be integrated with daily fire danger maps, based on meteorological conditions affecting fuel moisture content and related flammability. As an example, EFFIS (http://forest.jrc.ec.eu ropa.eu/effis/applications/current-situation/) daily maps of 1 to 6 days projected fire danger level, based on the Fire Weather Index can be used to further stratify forest typebased flammability maps, in order to improve the effectiveness of fire detection and allocation of fighting resources during critical days of the fire season.

\section{Acknowledgments}

The work was financed by the project
PRIN 2009 “in_FLAMING: Developing innovative models and techniques for integrated fuel management for fire prevention in Mediterranean and temperate forests" (coordinator: P. Corona) funded by the Italian Ministry for Education, University and Research.

\section{References}

Alessio GA, Peñuelas J, Llusià J, Ogaya R, Estiarte M, De Lillis M (2008). Influence of water and terpenes on flammability in some dominant Mediterranean species. International Journal of Wildland Fire 17: 274-286. - doi: 10.1071/WF07 038

Anderson HE (1970). Forest fuel ignitibility. Fire Technology 6 (4): 312-319. - doi: 10.1007/BF02 588932

Ascoli D, Bovio G (2013). Prescribed burning in Italy: issues, advances and challenges. iForest 6 : 79-89. - doi: 10.3832/ifor0803-006

Bajocco S, Ricotta C (2008). Evidence of selective burning in Sardinia (Italy): which land-cover classes do wildfires prefer? Landscape Ecology 23 (2): 241-248. - doi: 10.1007/s10980-007-917 6-5

Barbati A, Corona P, D'Amato E, Cartisano R (2013). Is landscape a driver of short-term wildfire recurrence? Landscape Research. - doi: 10.1080/01426397.2012.761681

Barbati A, Marchetti M, Chirici G, Corona P (2014). European forest types and forest Europe SFM indicators: tools for monitoring progress on forest biodiversity conservation. Forest Ecology and Management 321: 145-157. - doi: 10.1016/j. foreco.2013.07.004

Blasi C, Bovio G, Corona P, Marchetti M, Maturani A (2005). Fires and ecosystem complexity. From forest assessment to habitat restoration. Executive summary. Ministero dell'Ambiente e della Tutela del Territorio, Società Botanica Italiana, Palombi \& Partner, Rome, Italy, pp. 60.

Bovio G, Corona P, Leone V (2014). Gestione selvicolturale dei combustibili per la prevenzione degli incendi boschivi [Silvicultural management of forest fuels to prevent wildfires]. Compagnia delle Foreste, Arezzo, Italy, pp. 208. [in Italian]

CFS (2006). Rapporto annuale incendi boschivi [Annual report on forest fires]. Corpo Forestale dello Stato, Rome, Italy

Chiriacò MV, Perugini L, Cimini D, D'Amato E, Valentini R, Bovio G, Corona P, Barbati A (2013). Comparison of approaches for reporting forest fire-related biomass loss and greenhouse gas emissions in southern Europe. International Journal of Wildland Fire 22: 730-738. - doi: 10.1071/WF12011

Chirici G, Scotti R, Montaghi A, Barbati A, Cartisano R, Lopez G, Marchetti M, McRoberts RE, Olsson H, Corona P (2013). Stochastic gradient boosting classification trees for forest fuel types mapping through airborne laser scanning and IRS LISS-III imagery. International Journal of Applied Earth Observation and Geoinformation 25:87-97. - doi: 10.1016/j.jag.2013.04.006

CLC (2006). Corine Land Cover 2006. Web site. [online] URL: http://www.sinanet.isprambiente. it/it/sia-ispra/download-mais/corine-land-cover/ corine-land-cover-2000-iv-livello/view

EEA (2007). CLC2006 technical guidelines. EEA Technical report No $17 / 2007$, pp. 66. [online] URL: http://www.eea.europa.eu/publications/te chnical report $2007 \quad 17$

FAO (2001). Global forest resources assessment 2000. Main Report. FAO Forestry Paper 140, Rome, Italy, pp. 511. [online] URL: ftp://ftp.fao.org/docrep/fao/003/y1997E/frA\%202000\% 20Main\%20report.pdf

FAO (2006). Fire management: voluntary guidelines. Principles and strategic actions. Fire Management Working Paper 17, Rome, Italy, pp. 74. [online] URL: ftp://ftp.fao.org/docrep/fao/ 009/j9255e/j9255e00.pdf

Fernandes PM (2009). Combining forest structure data and fuel modelling to classify fire hazard in Portugal. Annals of Forest Science 66 (4): 415 415. - doi: 10.1051/forest/2009013

Fernandes PM, Cruz MG (2012). Plant flammability experiments offer limited insight into vegetation-fire dynamics interactions. New Phytologist 194 (3): 606-609. - doi: 10.1111/j.1469-8137.20 12.04065.x

Finney MA (1998). FARSITE: Fire Area Simulator-model development and evaluation. Research Paper RMRS-RP-4 Revised, Rocky Mountain Research Station, USDA Forest Service, Ogden, UT, USA, pp. 52. [online] URL: http://www.firemodels.org/downloads/farsite/publications/Finne y_1998_RMRS-RP-4.pdf

García M, Riaño D, Chuvieco E, Salas J, Danson FM (2010). Multispectral and LiDAR data fusion for fuel type mapping using Support Vector Machine and decision rules. Remote Sensing of Environment 115 (6): 1369-1379. - doi: 10.10 16/j.rse.2011.01.017

Gill AM, Zylstra P (2005). Flammability of Australian forests. Australian Forestry 68 (2): 87-93. - doi: 10.1080/00049158.2005.10674951

Heinsch FA, Andrews PL (2010). BehavePlus fire modeling system, version 5.0: design and features. Gen. Tech. Rep. RMRS-GTR-249, Rocky Mountain Research Station, USDA Forest Service, Ogden, UT, USA, pp. 124. [online] URL: http://www.fs.fed.us/rm/pubs/rmrs_gtr213.pdf INFC (2007). Le stime di superficie 2005. Prima parte. Inventario Nazionale delle Foreste e dei Serbatoi Forestali di Carbonio [Area estimates 2005. National Inventory of Forests and Forest Carbon Sinks] (Tabacchi G, De Natale F, Di Cosmo L, Floris A, Gagliano C, Gasparini P, Genchi L, Scrinzi G, Tosi V eds). MiPAF Corpo Forestale dello Stato - Ispettorato Generale, CRA-ISAFA, Trento, Italy, pp. 413. [in Italian] [online] URL: http://www.sian.it/inventarioforestale/jsp/documentazione.jsp

INFC (2009). I caratteri quantitativi 2005 - Prima parte, versione 2. Inventario Nazionale delle Foreste e dei Serbatoi Forestali di Carbonio [The quantitative attributes 2005. National Inventory of Forests and Forest Carbon Sinks] (Gasparini P, De Natale F, Di Cosmo L, Gagliano C, Salvadori I, Tabacchi G, Tosi V eds). MiPAAF - Is- 
pettorato Generale Corpo Forestale dello Stato, CRA-MPF, Trento, Italy. [online] URL: http:/ www.sian.it/inventarioforestale/jsp/documentazi one.jsp

ISPRA (2010). La realizzazione in Italia del progetto Corine Land Cover 2006 [The implementation in Italy of the project Corine Land Cover 2006]. Istituto Superiore per la Protezione e la Ricerca Ambientale, Report no. 131, Rome, Italy, pp. 49. [in Italian]

Keane RE, Burgan RE, van Wagtendonk J (2001). Mapping wildland fuels for fire management across multiple scales: integrating remote sensing, GIS, and biophysical modeling. International Journal of Wildland Fire 10: 301-319. doi: 10.1071/WF01028

Leone V, Saracino A, Trabaud L, Velez R (2000). Fire management and prevention policies in west Mediterranean pine forests. In: "Ecology, Biogeography and Management of Mediterranean Pine Forest Ecosystems (Pinus halepensis and $P$. brutia)" (Ne'eman G, Trabaud L eds). Backhuys
Publishers, The Hague, The Netherlands, pp. 335-354.

Madrigal J, Hernando C, Guijarro M, Diez C, Marino E, De Castro AJ (2009). Evaluation of fuel flammability and combustion properties with an adapted mass loss calorimeter device. Journal of Fire Sciences 27:323-342. - doi: 10.1177/0734904109102030

Manly B, McDonald L, Thomas D (1993). Resource selection by animals, statistical design and analysis for field studies. Chapman and Hall, London, UK, pp. 177. [online] URL: http://books.google.it/books? id=hNy8aM8HmrwC

Pezzatti GB, Bajocco S, Torriani D, Conedera M (2009). Selective burning of forest vegetation in Canton Ticino, southern Switzerland. Plant Biosystems 143 (3): 609-620. - doi: 10.1080/11263 500903233292

Stacey R, Gibson S, Hedley P (2012). European glossary for wildfires and forest fire ( $1^{\text {st }}$ edn). Northumberland Fire and Rescue Service, UK, pp. 138. [online] URL: http://www.fire.uni-frei
burg.de/literature/EUFOFINET-Fire-Glossary.pdf

Trabaud L (1976). Inflammabilité et combustibilité des principales espèces des garrigues de la region méditerranéennes [Flammability and combustibility of the main species of the garrigues in the French Mediterranean region]. Oecologia Plantarum 11 (2): 117-136. [in French]

White RH, Zipperer WC (2010). Testing and classification of individual plants for fire behaviour: plant selection for the wildland-urban interface. International Journal of Wildland Fire 19: 213 227. - doi: 10.1071/WF07128

Xanthopoulos G, Calfapietra C, Fernandes P (2012). Fire hazard and flammability of European forest types. In: "Post-fire management and restoration of Southern European forests" (Moreira F, Arianoutsou M, Corona P, De Las Heras G eds). Managing Forest Ecosystems 24, Springer, Berlin, Germany, pp. 79-92. 